\title{
BIODENTINE VERSUS MTA AS PULPOTOMY AGENTS IN PRIMARY MOLARS: CLINICAL AND RADIOGRAPHIC STUDY
}

\author{
Laila M. El Habashy*
}

\begin{abstract}
Objective: to compare the clinical and radiographic success rate of" Biodentine" to that of "mineral trioxide aggregates" (MTA) when used as "pulpotomy agents" in primary molars of children.

Study design: This split-mouth controlled randomized clinical study was performed on 10 healthy children age ranged from 2-6 years indicated for complete oral rehabilitation under general anaesthesia, with at least two carious primary molar indicated for pulpotomy. A total of thirty primary molars were treated, teeth were randomly assigned into two groups: Group A "Biodentine" group and Group B "MTA" group. All teeth were restored with "stainless steel crowns". Follow up was done after 6 and 12 months for clinical and radiographic assessment.
\end{abstract}

Results: clinical success rate was $100 \%$ in both group after12 months follow up period. Both groups showed internal root resorption (IRR) either at 6 or 12 months follow up. In the "Biodentine" group four teeth out of 15 showed internal root resorption (IRR) in the whole period of the study. In the "MTA" group two teeth showed IRR in the whole period of study. The radiographic success rate of Biodentine to MTA was $73.3 \%$ and $86.6 \%$ respectively, with no statistically significant difference between the two groups $(\mathrm{P}=0.65)$.

Conclusion: Using "Biodentine" and "MTA" as pulpotomy agent in primary teeth showed excellent clinical results. Radiographically, IRR was a finding in both groups. "Biodentine" showed more number of teeth with IRR but the difference was not statistically significant.

\section{INTRODUCTION}

"Pulpotomy" is the most frequently performed pulp therapy treatment in pediatric dentistry. ${ }^{(1)}$ The procedure has been described by Ranly to take one of three directions: "devitalization" (Fixation, as formocresol and cauterization as electrosurgery); "preservation" (non-inductive as ferric sulphate pulpotomy); and "regeneration" (inductive, reparative stimulate odontoblast to form dentin bridge as MTA and Biodentine). ${ }^{(2)}$

Formocresol (FC) was introduced by Buckley in 1904 and since then, it was considered as the "gold standard pulpotomy agent" for decades. This was due to its bactericidal and fixative characteristics,

\footnotetext{
* Associate Professor, Pediatric Dental Department, Alexandria University
} 
which resulted in high success rates. FC is made of "formaldehyde" and "cresol" (caustic agent), and although formaldehyde is a mutagenic and carcinogenic material, there was no evidence that when used as pulpotomy agent it can cause pathology to children. ${ }^{(3)}$ However, formaldehyde have been documented as carcinogenic occupational hazard substance related to leukaemia and nasopharyngeal cancer and its main toxic action is by inhalation, ${ }^{(4)}$ thus dentist and all dental staff can be affected by its harmful effect. This has led scientists to search for more biocompatible, and safer substitutes.

Torabinejad et al. ${ }^{(5)}$ in 1993, introduced a new bio-inductive and regenerative dental material "MTA" in the field of endodontics, the material is available as grey or white preparations; the latter has become more popular to avoid tooth discoloration. ${ }^{(6-8)}$ MTA is composed of fine hydrophilic particles that in the presence of water or moisture, forms a colloidal gel which solidifies to form hard cement within approximately four hours. The chemical composition of the grey "MTA" is "tricalcium oxide, tricalcium silicate, bismuth oxide, dicalcium silicate, tricalcium aluminate, tetracalcium aluminoferrite and calcium sulfate dehydrate", ${ }^{(9-12)}$ while the white MTA lacks the tetracalcium aluminoferrite. ${ }^{(13,14)}$ "MTA" has been used as successful medicament for vital pulp therapy procedures, ${ }^{(11,12)}$. It has the ability to induce effective dentinal bridge formation in a short period of time, with significantly lower inflammation and necrosis of the pulp tissue than calcium hydroxide, ${ }^{(14,15)}$ MTA has also showed to be a successful material when used as a pulpotomy agent in primary molars giving equal or even better success rates than formocresol. (7,15,16) However, MTA has some limitations regarding its physical properties, handling characteristics, and cost. To overcome these limitations, a new calcium silicate based material has been developed in 2009 in the biomaterials laboratory of the "University of the Mediterranean in Marseille, France", under the name of "Bio- dentine" as it was specifically designed as a "dentine replacement" material, it has a dentin like property that allows it to fill up the cavity maintaining good marginal seal. The powder is composed of "tricalcium silicate", with the addition of calcium carbonate (filler) and zirconium oxide (radio pacifier)". The liquid is a solution of "calcium chloride with a water-reducing agent". Calcium chloride was added to shorten the initial and final setting times, as it also accelerates the rate of early strength development. Thus, the major advantages of "Biodentine" over "MTA" are the rapid setting time (approximately 12 minutes) and earlier strong mechanical properties. ${ }^{(17)}$ This material has become popular in recent years due to its similarity to "MTA" that made its indications run parallel to that of "MTA" including "root perforations, apexification, retrograde fillings, pulp capping procedures", and as dentin replacement material in restorative dentistry. ${ }^{(18)}$ Primary teeth pulpotomy is another vital pulp treatment method in which "Biodentine" is indicated. ${ }^{(17)}$

"MTA" and "Biodentine" have been rivals that shared parallel concern during the past decade as regards their efficacy when used as pulpotomy agents on amputated primary pulp stump. (19-23) Nevertheless, a sharp definition on which one to choose in a particular case has not been clearly defined. However, pulpotomy is a critical procedure that demand the use of medicament that give long term success to save the child from repeating a tedious procedure that would be a step back in child behavior toward dentistry, and a great burden to parents. Therefore, more studies are still needed in this scope.

The aim of the present study was to compare the clinical and radiographic outcomes of "MTA" to "Biodentine" when used as pulpotomy agents in primary molars.

The null hypothesis was that there will be no difference in the clinical and radiographic outcomes between "MTA" and "Biodentine" through the whole period of the study. 


\section{METHODS:}

This study was written according to the "Consolidated Standards of Reporting trials" (CONSORT) statement (Figure 1). ${ }^{(24)}$

Study design: A "double-blinded, split-mouth, randomized, controlled" clinical study was done. Sample Selection: Ten healthy children who needed complete oral rehabilitation under general anesthesia from those attending the "Pediatric Dentistry and Oral Public Health Department, Faculty of Dentistry, Alexandria University", were

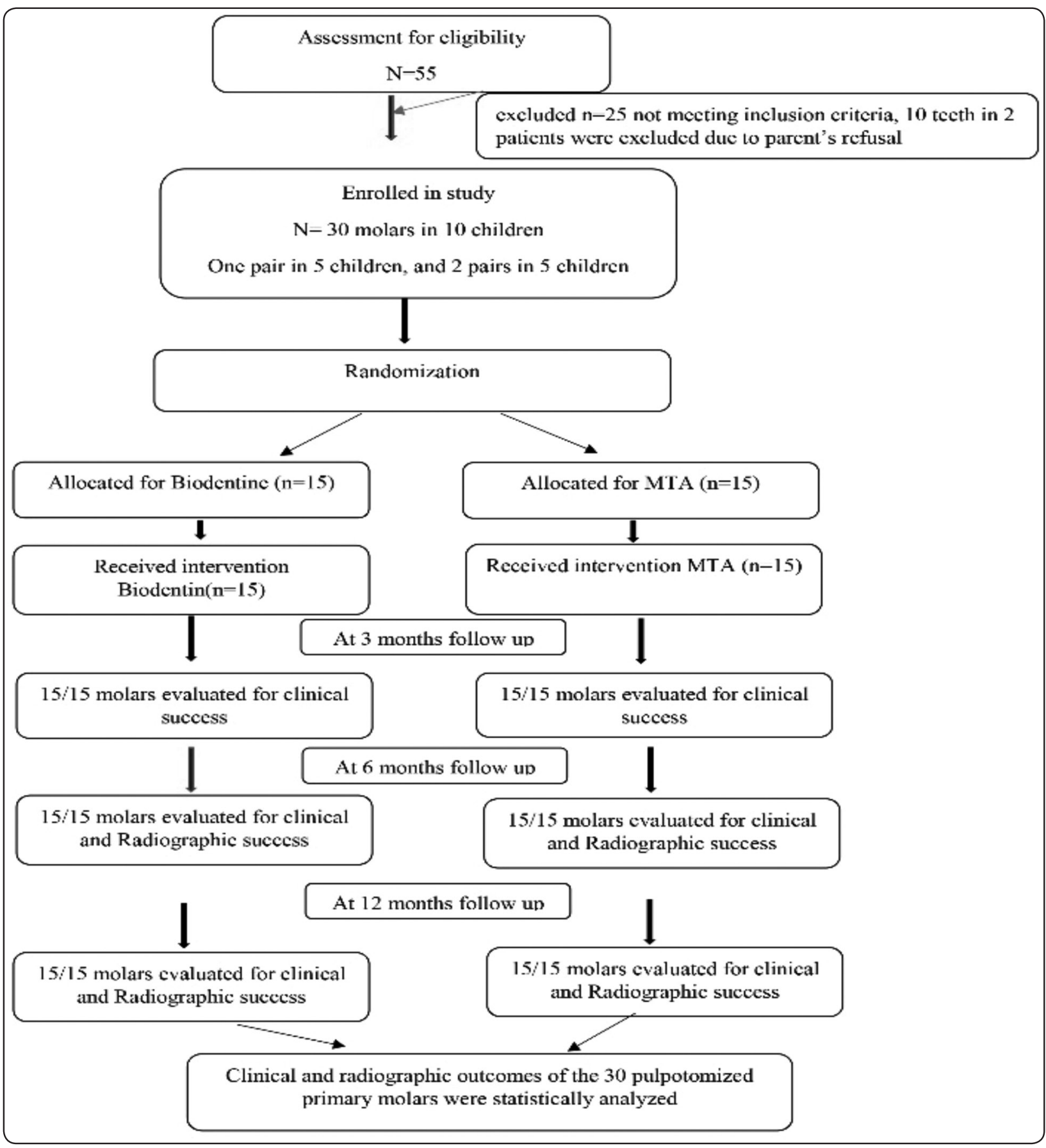

Fig. (1) CONSORT diagram showing study protocol up to 12 months follow up 
enrolled in this study. The children were five males and five females with age ranging from 2 to 6 years, mean $(\mathrm{SD})=3.9(1.3)$. Each child had at least one pair of primary molars indicated for pulpotomy. Written informed consents were obtained from the parents or guardians of children.

Teeth selection: was done according to the" American Academy of Pediatric Dentistry" (AAPD) guidelines, ${ }^{(25)}$ where all teeth were vital with deep carious lesion, healthy periodontium and absence of clinical signs or symptoms suggesting a non-vitality such as "suppurating sinus, soft tissue swelling, mobility or tenderness to percussion". Final case selection was based on direct evaluation of radicular pulp tissue after coronal pulp amputation, if the nature of bleeding from the amputated site was normal (light red color blood and hemostasis evident in less than 5 minutes with moist cotton pellet pressure) the pulp tissue in the canal were assumed to be normal and good candidate to be enrolled in the study. This ensured similar quality of pulp tissue in all cases of the 2 groups.

Sample size and power determination: The minimal sample size was calculated based on a previous study aimed to evaluate and compare "Biodentine" and "MTA" as pulpotomy agents by clinical and radiological assessments in primary teeth. Kamboj, et al. (2019) (26) concluded that "Biodentine" and "MTA" did not differ significantly in combined clinical and radiographic success after 6 months. Therefore, both can be considered reliable medicaments for pulpotomy treatment in primary teeth. Based on their results, adopting a power of $80 \%$ to detect a standardized effect size of 1.091 and level of significance $95 \%(\alpha=0.05)$, the minimum required sample size was found to be 15 teeth per group (number of groups $=2$ ) (Total sample size $=30$ teeth), ${ }^{(27)}$ is the minimum required sample size. Any withdrawal for any reason were compensated by replacement to control for attrition (withdrawal) bias. ${ }^{(28)}$ The sample size was calculated using GPower version 3.1.9.2. ${ }^{(29)}$
Randamization: The allocation sequence was generated using a "permuted block randomization technique", and the block size was variable. ${ }^{(30)}$ Allocation sequence/code was concealed from the person allocating the participants to the intervention arms using sealed opaque envelopes. ${ }^{(31)}$

Clinical Procedure: Complete isolation was achieved by rubber dam application, caries was then removed and coronal access was achieved to expose the pulp chamber using "high-speed" 330 carbide bur (Komet, Germany) with water coolant system. The coronal pulp tissue was then removed with sharp excavator and, hemostasis was achieved by applying moist cotton pellet for 2-3 minutes. "Pulpotomy" was completed by using one of the techniques which the tooth was assigned to. In Group A (Figure 2) the pulp stumps were covered with "Biodentine" ${ }^{\mathrm{TM}}$ Septodont, St. Maur-desFossés, France" according to the manufacturer's instruction: "Before the capsule of Biodentine was opened it was tapped gently to diffuse the powder. Five drops of the liquid were added to the powder and mixed in amalgamator for 30 seconds giving a paste that was gently applied to the pulp stump by mean of spatula and then condensed to fill the whole cavity". Working time was 6 minutes during which the material can be sculpted and only needed few more minutes for final setting. In Group B (Figure 3): "MTA, White Proroot, Dentsply, Tulsa Dental, USA" was prepared according to the manufacturer's instruction "MTA powder was mixed with distilled water at a 3:1 powder/water ratio and placed over the pulp stump, moisten cotton pallet was used to condense the material on the pulp stump", a thickness of 2-3 $\mathrm{mm}$ was applied covering the pulp stump and floor of pulp cavity. The rest of the cavity was then filled with "Zn oxide eugenol". All pulpotomized teeth were restored with "stainless steel crowns".

Follow up visits: The children were recalled after three months for clinical evaluation, followed by six, and 12 months for both clinical and radiographic assessment which was done by the same operator according to intra-rater agreement. ${ }^{(32)}$ Clinical 
criteria of failure included (25): "spontaneous pain, tenderness upon percussion, swelling, fistula, abscess or, abnormal mobility". Radiographic criteria of failure included (25): "widening of periodontal ligament (PDL), internal root resorption (IRR), pathological external root resorption, periapical or inter radicular radiolucency". Presence of one or more criterion was considered failure in treatment.

"Double blinded approach" was conducted to patients, and statistical analysis team. ${ }^{(33)}$

Statistical methodology: Data were collected and entered to the computer using "SPSS (Statistical Package for Social Science) program for statistical analysis (ver 21)". ${ }^{(34)}$ Data were entered as "numerical or categorical", as appropriate. "Kolmogorov-Smirnov" test of normality showed "no significance in the distribution of the variables", so the parametric statistics was adopted. ${ }^{(35)}$ Data were described using "minimum, maximum, mean, standard deviation and 95\% CI of the mean". (36) "Categorical variables" were described using "frequency and percentage". "Chi-square test" was used to test association between "qualitative variables". (37) "Fisher's Exact test" (38) was carried out when indicated (any expected cell less than 5). (39,40)" McNemar's test" was used on "paired nominal data" with matched pairs of teeth. ${ }^{(41)}$. "An alpha level was set to $5 \%$ with a significance level of $95 \%$, and a beta error accepted up to $20 \%$ with a power of study of $80 \% "$.

\section{Ethical considerations:}

Ethical approval was taken from the "Research Ethical Committee, Faculty of Dentistry Alexandria University" (IRP number IORG0008839).

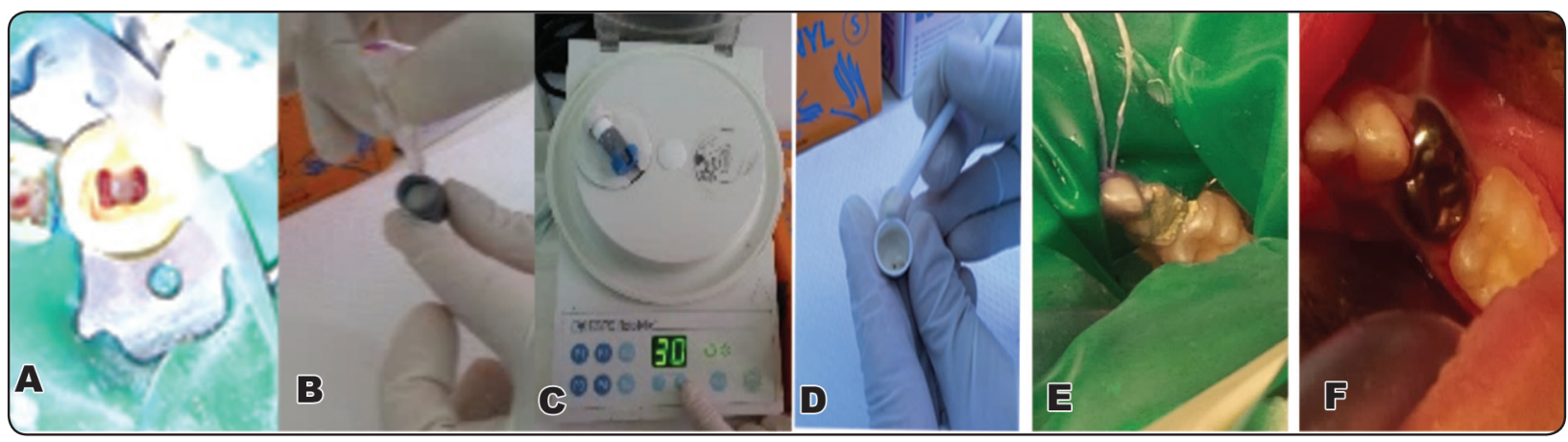

Fig. (2) photographs showing clinical steps of pulpotomy in "Biodentine" group: a. pulpotomized primary first molar, b. five drops of liquid added to powder, c. mixing for 30 second in amalgamator, d. paste ready to use, e. cavity filled with "Biodentine", f. tooth restored with SSC

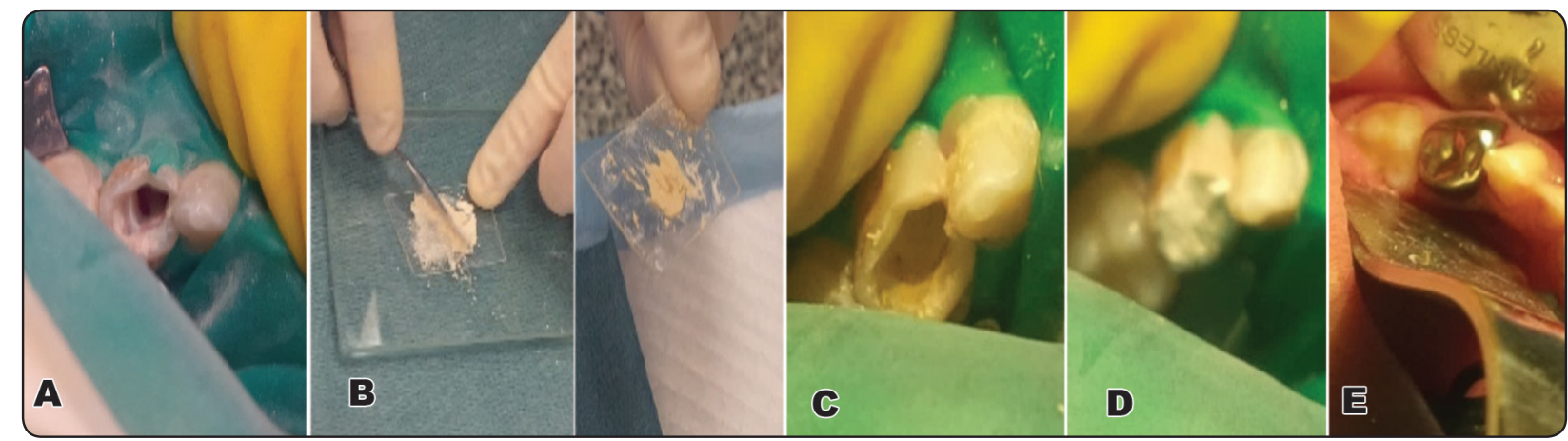

Fig. (3) photographs showing clinical steps of pulpotomy in "MTA" Group: a. pulpotomized molar, b. mixing MTA powder to liquid, c." MTA" covering root stump, d. cavity filled with IRM, e. tooth restored with SSC. 


\section{RESULTS}

All molars enrolled (no lost cases) in this study were clinically examined at three, six and 12 months post operatively. Radiographic evaluation was done at six, and 12 months postoperatively.

Table I: shows the "demographic characteristics' of this study. Thirty primary molars were included in the study: "first primary molars" $(18=60 \%)$ and "second primary molars" $(12=40 \%)$. In the "Biodentine" Group ten first primary molars (66.67\%), and five second primary molars $(33.33 \%)$ were treated, whereas in the "MTA" group eight first primary molar $(53.33 \%)$, and seven $(46.67 \%)$ second molars were treated. There was no significant difference regarding the type of teeth in both group $\mathrm{P}=0.456$.

The clinical results of this study showed $100 \%$ success rate in both groups (Figure 4).

The radiographic results showed high success rates in both "Biodentine" and "MTA": (84.62\%), and $(92.86 \%)$ respectively (Figure 5). The only negative radiographic findings in this study was the" internal root resorption" (IRR) (Figure 6,7).

Table II: shows the IRR outcomes in both groups at six and 12 months follow up: in this table per protocol analysis was performed where cases with negative outcomes were excluded from further analysis. Two teeth treated with Biodentine showed internal root resorption (IRR) at six months and were excluded from the 12 months' examination. One tooth treated with MTA showed internal root resorption (IRR) at 6 months and was excluded from the 12 months' examination The difference in cases showing internal root resorption between the two study groups at six months was not statistically significant $(p=1.000)$. At 12 months, two more Biodentine cases out of the remaining 13 showed internal root resorption compared to one out of the remaining 14 MTA cases. the difference at 12 months between the two groups in the number of cases showing internal root resorption was not statistically significant $(p=0.14)$.

Table III: shows the proportional relation in IRR in each group at six and 12 month follow up, there was no statistically significant difference between the scores of IRR at six or 12 month in neither Biodentine $(p=0.5)$ nor MTA group $(p=1.00)$.

Table IV and figure 8: show "intention to treat analysis" at the end of study, where all cases were analysed regardless of whether they were excluded because of negative outcomes before the end of the study. All over the study period, four Biodentin cases showed internal root resorption compared to two of the MTA cases with a no statistically significant difference between both groups $(\mathrm{P}=0.651)$.

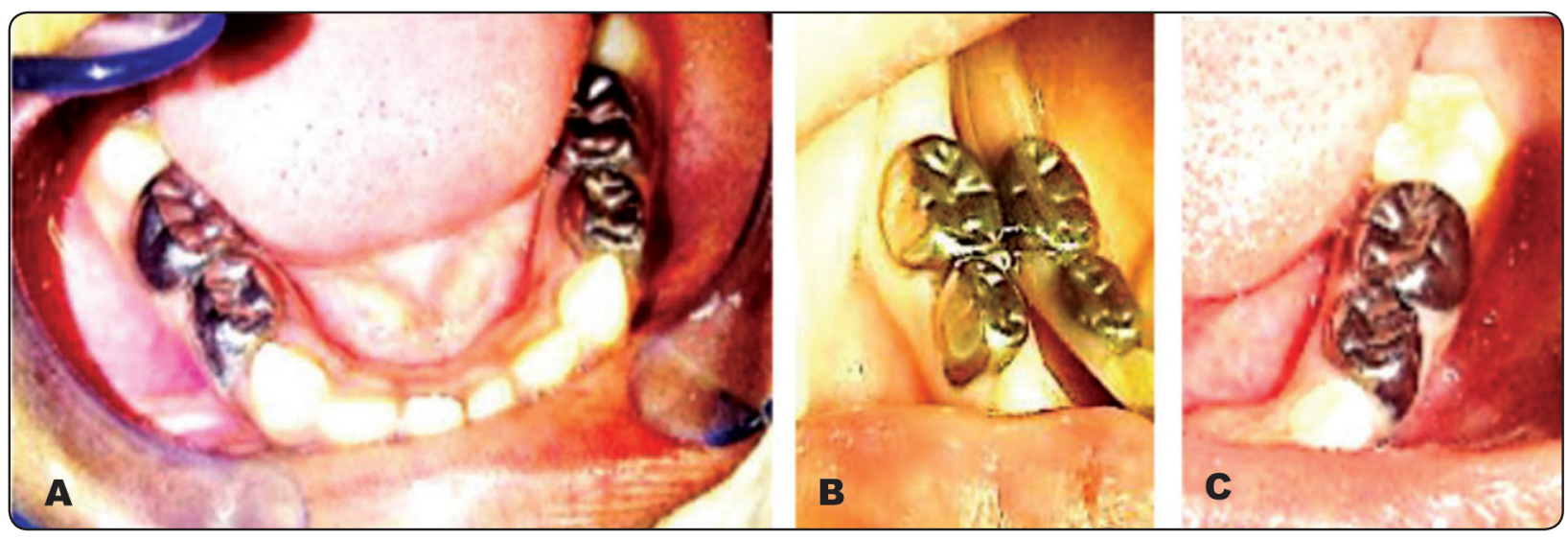

Fig. (4) a. photographs showing clinical success outcomes at 12 months in both groups, b. lower right first and second primary molars were pulpotomized using "Biodentine", c. lower left first and second primary molars were pulpotomized using "MTA". 


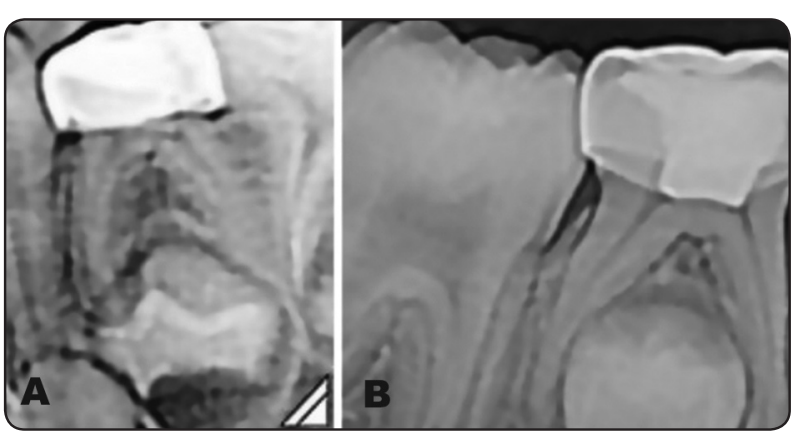

Fig. (5) Postoperative radiographs showing lower left primary first molars with successful outcome in both group at 12 months follow up period: a. Biodentine, b. MTA

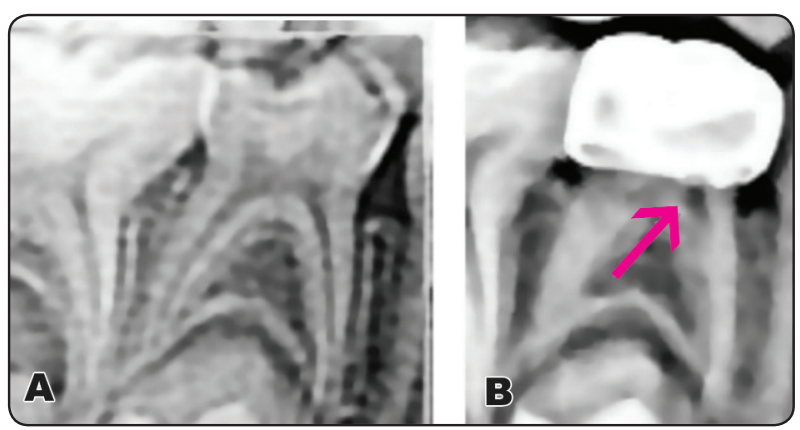

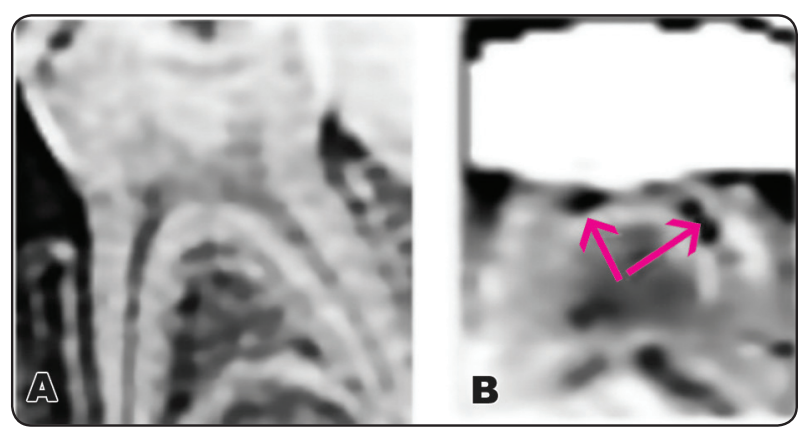

Fig. (6) Periapical x ray view showing lower left first primary molar in "Biodentine" group: a. pre-operative, b. after 12 months with IRR in both canals.

Fig. (7) Periapical x ray views showing lower right first primary molar in "MTA" group: a. pre-operative, b. after 12 months showing IRR in the mesial canal.

TABLE (1) Demographic, Clinical and Radiographic (other than IRR) Results in Both Studied Groups

\begin{tabular}{|c|c|c|c|}
\hline & \multicolumn{2}{|c|}{ Group } & \multirow{2}{*}{$\begin{array}{l}\text { Statistical test } \\
\quad \mathrm{p} \text { value }\end{array}$} \\
\hline & Biodentin & MTA & \\
\hline $\begin{aligned} \text { Age (years) } \\
-\quad \mathrm{n} \\
-\quad \text { Min-Max } \\
-\quad \text { Mean } \pm \text { S.D. } \\
-\quad 95 \% \text { CI of the mean }\end{aligned}$ & $\begin{array}{l}15 \\
2.00-6.00 \\
3.90 \pm 1.24 \\
3.21-4.59\end{array}$ & $\begin{array}{l}15 \\
2.00-6.00 \\
3.93 \pm 1.31 \\
3.21-4.66\end{array}$ & $\begin{array}{l}\mathrm{t}_{(\mathrm{df}=28)}=0.072 \\
\mathrm{p}=0.943 \mathrm{NS}\end{array}$ \\
\hline $\begin{aligned} \text { Sex } & \\
- & \text { Male } \\
- & \text { Female }\end{aligned}$ & $\begin{array}{l}5(33.33 \%) \\
10(66.67 \%)\end{array}$ & $\begin{array}{l}5(33.33 \%) \\
10(66.67 \%)\end{array}$ & NA \\
\hline $\begin{array}{l}\text { Type of teeth } \\
\begin{aligned}- & \text { First primary molar (D) } \\
- & \text { Second primary molar (E) }\end{aligned}\end{array}$ & $\begin{array}{l}10(66.67 \%) \\
5(33.33 \%)\end{array}$ & $\begin{array}{l}8(53.33 \%) \\
7(46.67 \%)\end{array}$ & $\begin{array}{l}\mathrm{c}_{(\mathrm{df}=1)}^{2}=0.556 \\
\mathrm{p}=0.456 \mathrm{NS}\end{array}$ \\
\hline
\end{tabular}

$n:$ number of patients

CI : Confidence interval

$c^{2}$ : Pearson Chi-Square test

NA : Non-applicable statistics (due to exact match)
Min-Max : Minimum to Maximum

$t:$ Student's $t$-test for equality of means

Df : degree of freedom

NS: Statistically not significant $(p \geq 0.05)$ 
TABLE (2) Comparison between Biodentin and MTA in internal root resorption after 6 and 12 months

\begin{tabular}{|l|l|c|c|}
\hline \multirow{2}{*}{ Groups at time points } & \multicolumn{2}{|c|}{ IRR } \\
\cline { 3 - 4 } & Biodentin & $2(13.33 \%)$ & $13(86.67 \%)$ \\
\cline { 2 - 4 } & MTA & $1(6.67 \%)$ & $14(93.33 \%)$ \\
\cline { 2 - 4 } & & \multicolumn{2}{|c|}{$\mathrm{c}_{(\mathrm{df}=1)}^{2}=0.370$} \\
\hline \multirow{3}{*}{12 months } & \multicolumn{2}{|c|}{$\mathrm{p}_{(\mathrm{FE})}=1.000 \mathrm{NS}$} \\
\cline { 2 - 4 } & Biodentin & $2(15.38 \%)$ & $11(84.62 \%)$ \\
\cline { 2 - 4 } & MTA & $1(7.14 \%)$ & $13(92.86 \%)$ \\
\cline { 2 - 4 } & & \multicolumn{2}{|c|}{$\begin{array}{c}\mathrm{c}_{(\mathrm{df}=1)}^{2}=0.464 \\
\mathrm{p}_{(\mathrm{FE})}=0.596 \mathrm{NS}\end{array}$} \\
\hline
\end{tabular}

FE: Fisher exact test

TABLE (4) Comparison between Biodentin and MTA in internal root resorption at the end of the study

\begin{tabular}{|l|l|l|}
\hline \multirow{2}{*}{ Group Type } & \multicolumn{2}{|l|}{ Internal root resorption } \\
\cline { 2 - 3 } & Yes & No \\
\hline Biodentin & $4(26.67 \%)$ & $11(73.33 \%)$ \\
\hline MTA & $2(13.33 \%)$ & $13(86.67 \%)$ \\
\hline Fisher exact test & $\begin{array}{l}\mathrm{c}^{2}(\mathrm{df}=1) \\
p_{(\mathrm{FE})}=0.6 .833 \\
0\end{array}$ \\
\hline
\end{tabular}

\section{DISCUSSION}

The null-hypothesis of this study was accepted as there was no significant differences between the two materials used in this study.

Recently, the bioactive material "MTA" has been stated by the AAPD to be "the most commonly used pulpotomy medicament" in primary teeth with higher clinical and radiographic success rates than "formocresol" and "ferric sulphate" (25). "Biodentine", is another new bioactive cement
TABLE (3) Exchange in proportions of IRR at 12 month Compared to 6 Months in both Groups

\begin{tabular}{|c|c|c|}
\hline \multirow[t]{2}{*}{ Group Type } & \multicolumn{2}{|c|}{ IRR (12 months) } \\
\hline & No & Yes \\
\hline \multicolumn{3}{|l|}{ Biodentin group } \\
\hline \multicolumn{3}{|l|}{ IRR (6 months) } \\
\hline No & $11(73.33 \%)$ & $2(13.33 \%)$ \\
\hline Yes & $0(0.00 \%)$ & $2(13.33 \%)$ \\
\hline \multirow[t]{2}{*}{$p$ value of McNemar test } & \multicolumn{2}{|c|}{$p=0.5 \mathrm{NS}$} \\
\hline & \multicolumn{2}{|c|}{ IRR (12 months) } \\
\hline MTA group & No & Yes \\
\hline \multicolumn{3}{|l|}{ IRR (6 months) } \\
\hline No & $13(86.67 \%)$ & $1(6.67 \%)$ \\
\hline Yes & $0(0.00 \%)$ & $1(6.67 \%)$ \\
\hline$p$ value of McNemar test & \multicolumn{2}{|c|}{$p=1.000 \mathrm{NS}$} \\
\hline
\end{tabular}

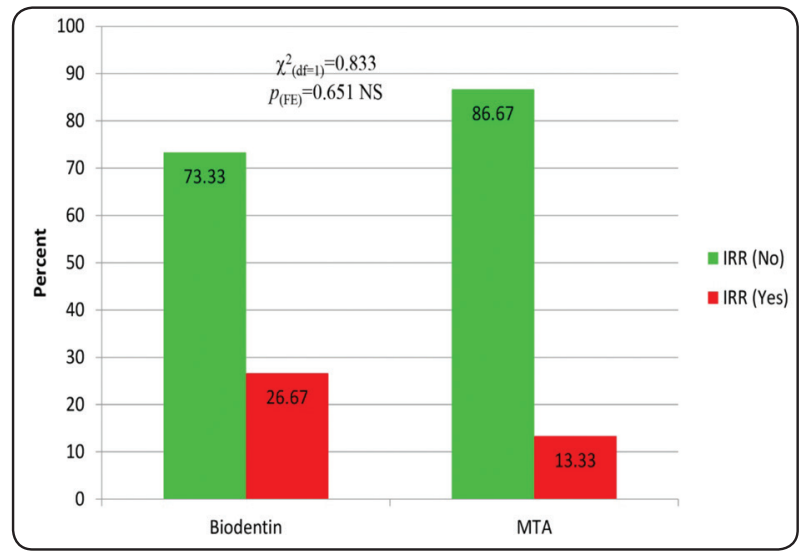

Fig. (8) Bar graph showing Internal root resorption in both study groups.

that is similar to "MTA" with improved physical and handling properties, ${ }^{(17)}$ as the material sets within 12 minutes only compared to four hours taken by MTA. This study was done to compare the "clinical and radiographic" outcomes of these two "Bioactive" materials: the new "Biodentine" compared to "MTA" when used as "pulpotomy" agents in primary molars

In this study the AAPD guide lines were adopted in case selection for vital pulpotomy to ensure 
long term success rates of the treatment. ${ }^{(25)}$ The present study was performed on children who need complete oral rehabilitation under general anesthesia for better standardization excluding any variables in child behavior that might affect the treatment, and to ensure complete control on the operative field. The study was a split moth design to remove any individual variations that would affect success or failure of the treatment. The results of the present study showed that there was no clinical or radiograpghical statistical significant difference between "Biodentine" and "MTA" when used as pulpotomy agents in primary teeth this was supported by other studies that recorded the same findings (19-23)

Both "Biodentine" and "MTA" groups showed $100 \%$ clinical success throughout the whole period of this study (12 months), this was in agreement with Juneja, et al 2017. (21) However, this finding was inconsistent with, Niranjani et al. ${ }^{(19)}$ who recorded clinical failure in two teeth in the "Biodentine" group out of 20 teeth after 6 months, represented as swelling and pain. Their explanation for the failures was related to iatrogenic errors as "bad selection of the cases, poor adaption of stainless steel crowns, residual caries or coronal pulp tissue". On the other hand, in the present study the absence of clinical failures might be attributed to the careful selection of cases, any case that represented excessive bleeding from the root stump was excluded immediately even if the preoperative radiographs were free from any contraindications to pulpotomy. Another important factor as mentioned above; is that the treatment was carried under general anaesthesia that allowed mastering of the operative field, moreover, treatment was done under complete isolation using rubber dam, no residual caries or pulp tissue in the pulp chamber were left, finally, snugly fit crowns were selected to ensure long term treatment.

Although there was no statistical significant difference in the radiographic findings between the two groups in this study, yet "MTA" showed better radiographic outcomes than "Biodentine". In the "MTA" group only one tooth showed IRR after six month compared to two teeth in "Biodentine" group, and at 12 month follow up "MTA" showed one more tooth with IRR compared to two in "Biodentine" group. These findings were in accordance to Juneja, et al. (2017) ${ }^{(21)}$ who reported in a similar study that MTA showed better radiographic results than Biodentine, in their study "MTA" group didn't show any radiographic failure in the whole 18 months follow up, whereas "Biodentine" showed one tooth with IRR after 12 months, and at 18 months two teeth showed IRR. Moreover, in another study done by Celik et al, 2019, (22) they found that the radiographic success rate of "MTA" to "Biodentine" was $100 \%$ to $89.4 \%$ respectively but still there was no statistically significant difference.

Since, "Biodentin" and "MTA" has proved to induce "cytokine release" and consequently stimulate bone or dentin matrix deposition in the permanent teeth, ${ }^{(17,42,43)}$ therefore, the IRR encountered in "Biodentine" and "MTA" samples of this study would be questionable. This might be due to the difference in the nature between permanent and primary teeth. It is well known that the function of cytokine depends on the type tissue receptor, thus it can be assumed that the primary pulp odontoclast were stimulated by the high alkalinity of both materials rather than the odontoblast cells leading to IRR rather than dentin deposition. ${ }^{(43)}$ Hence, the overstimulation induced caused metaplasia within the pulp tissue, leading to the formation of odontoclast cells which resulted in the IRR in both groups.

The fact that "Biodentine" group showed more cases of IRR than "MTA" group in the present study can be attributed to the different setting time between the two materials. The "MTA" needs at least four hours to set compared to "Biodentine" that set within few minutes. Thus the rapid setting of the 
"Biodentine" might have induced a sudden increase in the $\mathrm{pH}$ of the material and caused irritation to the radicular pulp tissue, whereas the longer time taken by the MTA to set might have allowed gradual increase in the $\mathrm{pH}$ of the material and thus did not produce a "shocking" effect on the pulp tissue. However, for better understanding of primary pulp response to the materials more histological studies are still needed.

In this study the only Radiographic finding in both group was the IRR while in other studies other findings were reported as furcation involvement and widening in PDL both in "MTA" and "Biodentine" pulpotomies. ${ }^{(3,20)}$ This might be due to the strict judgment in case selection of this study excluding any chance of inflammation left over in the radicular pulpal tissue.

\section{Based on the findings of the present study the following can be concluded:}

1. Using "Biodentine" and "MTA" as a pulpotomy agent in primary teeth showed excellent clinical results $(100 \%$ success rate).

2. Internal root resorption was a radiographic finding in both groups

3. Biodentine showed more teeth with IRR than MTA but the difference was not Statistically significant.

RECOMMENDATION: long term clinical and radiographic studies are needed to check the progress of the "internal root resorption", and if it might lead to early tooth loss.

\section{REFERENCES}

1. Mcdonald RE, Avery DR, Dean JA. Dentistry For The Child And Adolescent (8Th Edition): Elsevier (A Divisionof Reed Elsevier India Pvt. Limited); 2004. 406-8 p.

2. Ranly DM. Pulpotomy therapy in primary teeth: new modalities for old rationales. Pediatric dentistry. 1994; 16(6): 403-9.
3. Simancas-Pallares MA, Diaz-Caballero AJ, LunaRicardo LM. Mineral trioxide aggregate in primary teeth pulpotomy. A systematic literature review. Medicina oral, patologia oral y cirugia bucal. 2010; 15(6): e942-6.

4. International Agency for Researsh on Cancer World health Organization. 2004. Available from: http://www.iarc.fr/en/ medis-center/pr/2004/pr153.htm.

5. Torabinejad M, Watson TF, Pitt Ford TR. Sealing ability of a mineral trioxide aggregate when used as a root end filling material. Journal of endodontics. 1993; 19(12): 591-5.

6. Al-Hezaimi K, Al-Hamdan K, Naghshbandi J, Oglesby S, Simon JH, Rotstein I. Effect of white-colored mineral trioxide aggregate in different concentrations on Candida albicans in vitro. Journal of endodontics. 2005; 31(9): 684-6.

7. Maroto M, Barberia E, Planells P, Garcia Godoy F. Dentin bridge formation after mineral trioxide aggregate (MTA) pulpotomies in primary teeth. American journal of dentistry. 2005 ; 18(3): 151-4.

8. Parirokh M, Asgary S, Eghbal MJ, Stowe S, Eslami B, Eskandarizade A, et al. A comparative study of white and grey mineral trioxide aggregate as pulp capping agents in dog's teeth. Dental traumatology : official publication of International Association for Dental Traumatology. 2005; 21(3): 150-4.

9. Torabinejad M, Hong CU, Pitt Ford TR, Kettering JD. Cytotoxicity of four root end filling materials. Journal of endodontics. 1995; 21(10): 489-92.

10. Torabinejad M, Rastegar AF, Kettering JD, Pitt Ford TR. Bacterial leakage of mineral trioxide aggregate as a rootend filling material. Journal of endodontics. 1995; 21(3): 109-12.

11. Abedi HR, Ingle JI. Mineral trioxide aggregate: a review of a new cement. Journal of the California Dental Association. 1995; 23(12): 36-9.

12. Torabinejad M, Hong CU, McDonald F, Pitt Ford TR. Physical and chemical properties of a new root-end filling material. Journal of endodontics. 1995; 21(7): 349-53.

13. Ferris DM, Baumgartner JC. Perforation repair comparing two types of mineral trioxide aggregate. Journal of endodontics. 2004; 30(6): 422-4.

14. Stowe TJ, Sedgley CM, Stowe B, Fenno JC. The effects of chlorhexidine gluconate $(0.12 \%)$ on the antimicrobial properties of tooth-colored ProRoot mineral trioxide aggregate. Journal of endodontics. 2004; 30(6): 429-31. 
15. Farsi N, Alamoudi N, Balto K, Mushayt A. Success of mineral trioxide aggregate in pulpotomized primary molars. The Journal of clinical pediatric dentistry. 2005; 29(4): 307-11.

16. Holan G, Eidelman E, Fuks AB. Long-term evaluation of pulpotomy in primary molars using mineral trioxide aggregate or formocresol. Pediatric dentistry. 2005; 27(2): 129-36.

17. Malkondu Ö, Kazandağ MK, Kazazoğlu E. A review on biodentine, a contemporary dentine replacement and repair material. BioMed research international. 2014; 2014.

18. Grech L, Mallia B, Camilleri J. Investigation of the physical properties of tricalcium silicate cement-based root-end filling materials. Dental materials : official publication of the Academy of Dental Materials. 2013; 29(2): e20-8.

19. Niranjani K, Prasad MG, Vasa AAK, Divya G, Thakur MS, Saujanya K. Clinical Evaluation of Success of Primary Teeth Pulpotomy Using Mineral Trioxide Aggregate ${ }^{\circledR}$, Laser and BiodentineTM-an In Vivo Study. Journal of clinical and diagnostic research: JCDR. 2015; 9(4): ZC35.

20. Kusum B, Rakesh K, Richa K. Clinical and radiographical evaluation of mineral trioxide aggregate, biodentine and propolis as pulpotomy medicaments in primary teeth. Restorative dentistry \& endodontics. 2015; 40(4): 276-85.

21. Juneja P, Kulkarni S. Clinical and radiographic comparison of biodentine, mineral trioxide aggregate and formocresol as pulpotomy agents in primary molars. European archives of paediatric dentistry : official journal of the European Academy of Paediatric Dentistry. 2017; 18(4): 271-8.

22. Celik BN, Mutluay MS, Arikan V, Sari S. The evaluation of MTA and Biodentine as a pulpotomy materials for carious exposures in primary teeth. Clin Oral Investig. 2019; 23(2): 661-6.

23. Stringhini Junior E, Dos Santos MGC, Oliveira LB, Mercade M. MTA and biodentine for primary teeth pulpotomy: a systematic review and meta-analysis of clinical trials. Clin Oral Investig. 2019; 23(4): 1967-76.

24. Moher D, Hopewell S, Schulz KF, Montori V, Gotzsche P, Devereaux P, et al. CONSORT 2010 statement: updated guidelines for reporting parallel group randomised trials. BMJ (Clinical research ed). 2010; 340: c332.

25. Guideline on Pulp Therapy for Primary-and Immature Permanent Teeth. AAPD Reference Manual. 2012; 33: 213-18.
26. Kamboj V, Gupta M, Pandit I, Gugnani N. Comparative Evaluation of Mineral Trioxide Aggregate and Biodentine as Pulpotomy Agents in Primary Molars-An In Vivo Study. International Journal of Science and Healthcare Research. 2019; 4(4): 160-7.

27. Charan J, Biswas T. How to calculate sample size for different study designs in medical research? Indian journal of psychological medicine. 2013; 35(2): 121-6.

28. Pannucci CJ, Wilkins EG. Identifying and avoiding bias in research. Plastic and reconstructive surgery. 2010; 126(2): 619-25.

29. Faul F, Erdfelder E, Lang A-G, Buchner A. G* Power 3: A flexible statistical power analysis program for the social, behavioral, and biomedical sciences. Behavior research methods. 2007; 39(2): 175-91.

30. Schulz KF, Grimes DA. Generation of allocation sequences in randomised trials: chance, not choice. The Lancet. 2002; 359(9305): 515-9.

31. Schulz KF, Grimes DA. Allocation concealment in randomised trials: defending against deciphering. The Lancet. 2002; 359(9306): 614-8.

32. Kayapınar U. Measuring essay assessment: Intra-rater and inter-rater reliability. Eurasian Journal of Educational Research. 2014; (57): 113-36.

33. Karanicolas PJ, Farrokhyar F, Bhandari M. Blinding: Who, what, when, why, how? Can J Surg. 2010; 53(5): 345.

34. IBM Corp. IBM SPSS Statistics for Windows, Version 21.0. Armonk, NY: IBM Corp.; Released 2012.

35. Field A. Discovering statistics using IBM SPSS statistics: sage; 2013.

36. Snecdecor G, Cochran W. Statistical Methods, vol. 276. Wiley, NJ; 1991.

37. Pearson K. X. On the criterion that a given system of deviations from the probable in the case of a correlated system of variables is such that it can be reasonably supposed to have arisen from random sampling. The London, Edinburgh, and Dublin Philosophical Magazine and Journal of Science. 1900; 50(302): 157-75.

38. Fisher RA. On the interpretation of $\chi 2$ from contingency tables, and the calculation of P. Journal of the Royal Statistical Society. 1922; 85(1): 87-94.

39. Smith PW, Forster JJ, McDonald JW. Monte Carlo exact tests for square contingency tables. Journal of the Royal 
Statistical Society: Series A (Statistics in society). 1996; 159(2): 309-21.

40. Haviland MG. Yates's correction for continuity and the analysis of $2 \times 2$ contingency tables. Statistics in medicine. 1990; 9(4): 363-7.

41. Mc Nemar Q. Note on the sampling error of the difference between correlated proportions or percentages. Psychometrika. 1947; 12(2): 153-7.
42. Cox CF, Subay RK, Ostro E, Suzuki S, Suzuki SH. Tunnel defects in dentin bridges: their formation following direct pulp capping. Operative dentistry. 1996; 21(1): 4-11.

43. Nowicka A, Lipski M, Parafiniuk M, Sporniak-Tutak K, Lichota D, Kosierkiewicz A, et al. Response of human dental pulp capped with biodentine and mineral trioxide aggregate. Journal of endodontics. 2013; 39(6): 743-7. 